\title{
Sintomas de deficiências de macronutrientes em melancieira
}

\author{
Leonardo Correia Costa*, Victor Manuel Vergara Carmona, Arthur Bernardes Cecílio Filho, \\ Camila Seno Nascimento, Carolina Seno Nascimento
}

Universidade Estadual Paulista Jaboticabal, SP, Brasil

*Autor correspondente, email: leonardocorreia08@gmail.com

\begin{abstract}
Resumo
O manejo inadequado de corretivos e fertilizantes pode desencadear desordens nutricionais. Objetivou-se descrever e retratar a evolução dos sintomas de deficiências de nutrientes em melancieira quando induzidos no estádio de frutificação, e determinar o teor foliar no órgão e no momento em que foi visualizado o sintoma. $O$ experimento foi instalado em hidroponia. Os sintomas de deficiências $\mathrm{N}$ e Ca foram os primeiros a serem observados. A deficiência de $\mathrm{N}$ causou cessação do crescimento, inibição de hastes laterais, clorose generalizada e necrose em folhas velhas. Os sintomas da deficiência de $\mathrm{P}$ apareceram inicialmente em folhas velhas, com áreas cloróticas e enrugadas, que posteriormente progrediram para necrose. A deficiência de $\mathrm{K}$ causou clorose marginal em folhas velhas, progredindo para todo o limbo e evoluindo para necrose. Com a deficiência de $\mathrm{Ca}$, as folhas novas ficaram deformadas, com clorose e necrose marginal, margens encurvadas para baixo, limbo foliar grosso, enrugado e com necrose nos meristemas. A omissão de Mg inicialmente provocou sintomas de clorose internerval nas folhas velhas, com evolução para tecidos esbranquiçados e necróticos. Os teores de N, P, K, Ca e Mg na folha e por ocasião de deficiência foram 9,$7 ; 1,4 ; 7,1 ; 1,8$ e $1,8 \mathrm{~g} \mathrm{~kg}^{-1}$, respectivamente.
\end{abstract}

Palavras-chave: Citrullus lanatus, diagnóstico nutricional, nutrição mineral

\section{Symptoms of deficiencies macronutrients in watermelon}

\begin{abstract}
Improper handling of lime and fertilizer can trigger nutritional disorders. This study aimed at describing and depicting the evolution of the symptoms of nutrient deficiencies in watermelon when induced in the fruiting stage, and determining the leaf content in the organ and at the time the symptom was visualized. The experiment was in hydroponics. The symptoms of $\mathrm{N}$ and Ca deficiencies were the first to be observed. Nitrogen deficiency caused cessation of growth, inhibition of lateral rods, general chlorosis and necrosis in older leaves. Symptoms of $\mathrm{P}$ deficiency first appeared in old leaves with chlorotic and wrinkled areas, which later progressed to necrosis. K deficiency caused marginal chlorosis in older leaves, progressing to the entire limb and evolving to necrosis. With calcium deficiency, the new leaves were deformed, with marginal chlorosis and necrosis, curved edges down, thick leaf blade, wrinkled and necrosis in meristems. The Mg omission initially caused symptoms of internerval chlorosis in old leaves, progressing to off-white and necrotic tissues. The levels of $\mathrm{N}, \mathrm{P}, \mathrm{K}, \mathrm{Ca}$ and $\mathrm{Mg}$ in the leaf and on the occasion of deficiency were $9.7 ; 1.4 ; 7.1 ; 1.8$ to $1.8 \mathrm{~g} \mathrm{~kg}-1$, respectively.
\end{abstract}

Key words: Citrullus lanatus, nutritional diagnosis, mineral nutrition 


\section{Introdução}

Os nutrientes desempenham funções específicas no metabolismo da planta, e o fornecimento aquém do necessário, causa desordem fisiológica que afeta negativamente a produtividade da cultura e a qualidade da hortaliça colhida.

A avaliação do estado nutricional das culturas deve ser preferencialmente realizada precocemente, para que sejam possíveis implementar ações para correção de eventual deficiência ainda no mesmo cultivo. É o caso da diagnose foliar. Contudo, em hortaliças, o ciclo cultural é muito curto e, na maioria dos casos, a amostragem para avaliação do estado nutricional pelo método de diagnose foliar é realizada entre a metade e dois terços do ciclo, como é o caso da melancieira (Trani \& Raij, 1997). Soma-se a este, o tempo demandado para envio da amostra ao laboratório, seu processamento e determinação dos teores de nutrientes, e retorno da informação ao produtor, que juntos dificilmente proporcionam tempo para a correção da deficiência, se necessária.

Em razão da dificuldade apresentada, a diagnose visual tem importância no contexto de avaliação do estado nutricional da planta (Ayala-silva \& Beyl, 2005), ainda que seja uma técnica tardia de diagnose, pois sabe-se que o sintoma da deficiência é o último evento de uma série que se iniciou a nível molecular (Fan et al. 2014).

A criação de um banco de dados com fotografias e descrições minuciosas dos sintomas das deficiências nutricionais específicos para cada espécie podem contribuir para sucesso na avaliação do técnico ou produtor. Embora haja na literatura descrição dos sintomas de deficiência de nutrientes, a expressão das desordens nutricionais pode ter variações inter e intraespécie (Hawkesford et al., 2012). Outra questão é que os sintomas de deficiência nutricional em plantas também podem ser confundidos com sintomas desencadeados por estressores bióticos ou abióticos (Wiwart et al., 2009).

Na cultura da melancieira, os trabalhos existentes não contemplam os sintomas de todos os nutrientes nem a descrição da evolução dos sintomas. Além disso, não há trabalhos que associem o teor de nutriente com o aparecimento dos sintomas de deficiência nutricional, induzidos no estádio de frutificação. Em geral, as literaturas trazem a faixa de suficiência de nutrientes na folha.

Neste contexto, o trabalho foi realizado com o objetivo de descrever e retratar a evolução dos sintomas de deficiências em melancieira quando induzidos no estádio de frutificação, e determinar o teor foliar do macronutriente no órgão em que foi visualizado o sintoma causador da deficiência.

\section{Material e Métodos}

O experimento foi conduzido entre 6 de março a 10 de maio de 2014, em hidroponia, no sistema nutrient film technique (NFT), na UNESP, Campus Jaboticabal, situada a 21015'22" Sul e 48 18'58' 'Oeste, com altitude de 575 metros.

O delineamento experimental adotado foi inteiramente casualizado, com seis tratamentos (solução nutritiva completa (SNC) e as omissões de nitrogênio, fósforo, potássio, cálcio e magnésio) e três repetições. Cada unidade experimental continha quatro plantas, em canal de PVC, com 2,0 m de comprimento e $0,20 \mathrm{~m}$ de diâmetro, cortado ao meio no sentido longitudinal, e um reservatório de $100 \mathrm{~L}$, com bomba submersa marca Chosen, modelo Power Head CX-300, com vazão de $1000 \mathrm{~L} \mathrm{~h}^{-1}$. O canal foi coberto com Tetrapak ${ }^{\circledR}$ para evitar incidência de radiação na solução nutritiva. 0 bombeamento das soluções nutritivas às plantas ocorreu de 6 às 18h, sem interrupção.

As mudas de melancieira 'Crimson Sweet' foram formadas em espuma fenólica, com dimensões de $5 \times 5 \times 3 \mathrm{~cm}$, lavada previamente em água corrente, por 10 minutos. Dez dias após a semeadura, quando as plântulas apresentavam duas folhas cotiledonares expandidas, foram levadas para os canais de crescimento inicial, sistema hidropônico NFT, com recirculação da solução nutritiva, cujos canais hidropônicos de PVC tinham $5 \mathrm{~cm}$ de diâmetro, onde permaneceram por dezesseis dias. Então, as mudas, que apresentavam quatro folhas definitivas expandidas foram transplantadas para os canais hidropônicos, com diâmetro de 
$20 \mathrm{~cm}$

Tanto nos canais de crescimento inicial e final, as plantas receberam solução nutritiva proposta por Hoagland \& Arnon (1950), cujas concentrações, em mg L-1, foram: 14 de $\mathrm{N}^{-N_{4}}{ }_{4}^{+}$, 196 de $\mathrm{N}_{-\mathrm{NO}_{3}}^{-}, 31$ de $\mathrm{P}, 234,6$ de K, 200 de $\mathrm{Ca}, 46$ de S, 64 de Mg, 5 de Fe, 0,5 de Mn, 0,5 de B, 0,02 de Cu, 0,05 de Zn e 0,01 de Mo. Os fertilizantes utilizados no preparo da solução completa e das soluções com omissão de nutrientes foram nitrato de potássio, nitrato de cálcio, nitrato de amônio, cloreto de cálcio, cloreto de potássio, monoamônio fosfato, fosfato monobásico de potássio, sulfato de magnésio, sulfato de potássio, acetato de cálcio, acetato de potássio, ácido nítrico, ácido sulfúrico, sulfato de cobre, sulfato de manganês, sulfato de zinco, ácido bórico, ferro quelatizado por EDDHMA e molibdato de amônio.

No dia 13 de abril, 38 dias após a semeadura, quando as plantas estavam em início de frutificação, foram omitidos N, P, Ca, Mg e S de seus respectivos tratamentos e no tratamento omissão de $\mathrm{K}$ esse nutriente foi mantido a $10 \%$ da concentração na solução nutritiva completa. Devido a água de abastecimento da hidroponia conter $19 \mathrm{mg} \mathrm{L}^{-1}$ de cálcio, foi utilizada água deionizada no tratamento com omissão desse nutriente. No dia 24 de abril, realizou-se a omissão de K no tratamento omissão de K.

$\mathrm{O} \mathrm{pH}$ e a condutividade elétrica (CE) das soluções nutritivas foram monitoradas a cada dois dias. $\mathrm{O} \mathrm{pH}$ das soluções nutritivas foi mantido entre 6,0 e 6,5 com a utilização de ácido sulfúrico para baixar o $\mathrm{pH}$ e de hidróxido de sódio para aumentar o pH. A CE das soluções nutritivas foram mantidas entre 1,8 a 2,2 dS $\mathrm{m}^{-1}$ com adição de solução nutritiva estoque de mesma concentração e água. A solução estoque foi armazenada em reservatórios de polietileno com capacidade de 1000 L. A cada 15 dias, as soluções nutritivas dos tratamentos foram renovadas.

O espaçamento adotado foi de 1,1 m entre canais de cultivo e 0,50 m entre plantas no canal. As hastes das plantas cresceram sobre o solo e quando a haste principal da planta atingiu cerca de 1,5 m foi conduzida no sentido vertical, utilizando fita plástica. Não se fez desbrotas das hastes laterais, visando maior área foliar, aumento da demanda nutricional e possibilidade de ocorrer os sintomas de deficiência nutricional.

Os sintomas de deficiência dos macronutrientes foram descritos e registrados em fotografias, assim como também foram determinados os teores do nutriente omitido no momento da visualização da deficiência. Em plantas cultivadas na solução nutritiva completa (tratamento controle) foi avaliado o estado nutricional na quinta folha da ponta da haste para a base, excluindo o tufo apical (Trani \& Raij, 1997), quando estava iniciando-se a frutificação. Os teores de nutrientes foram determinados conforme métodos descritos por Bataglia et al. (1983). Ao final do experimento, foi realizada a coleta de uma planta por unidade experimental e verificado o acúmulo de massa seca.

\section{Resultados e Discussão}

Nitrogênio ( $N$ )

O sintoma visual de deficiência de $\mathrm{N}$ foi observado 7 dias após a omissão (DAO) do N na solução nutritiva, quando a planta contava com 45 dias de ciclo e alta demanda de N. O surgimento do sintoma coincidiu com a época de maior demanda por $\mathrm{N}$, semelhante ao observado para as melancieiras 'Shadow' e 'Crimson Sweet' que, de acordo com Grangeiro \& Cecílio Filho (2005), ocorre entre 42 e 56 dias após o transplante.

A deficiência de $\mathrm{N}$ foi caracterizada pela cessação do crescimento e clorose nas folhas velhas, situadas até o quarto nó, da base para o ápice da planta, das três hastes principais. As demais folhas apresentaram cor verde considerada normal quando comparadas às plantas da solução completa (Figura 1). A cessação do crescimento e clorose generalizada nas folhas velhas após omissão de $\mathrm{N}$ também foi observado em pepino (Ji-Yong et al., 2012). A clorose em folhas velhas deficientes em $\mathrm{N}$ ocorre devido à degradação de proteínas nos estromas para liberação de compostos nitrogenados, entre eles os aminoácidos (Feller et al., 2008), que leva à perda da integridade do cloroplasto devido à desestruturação da grana e lamela do estroma (Bondada \& Syvertsen, 2003). 


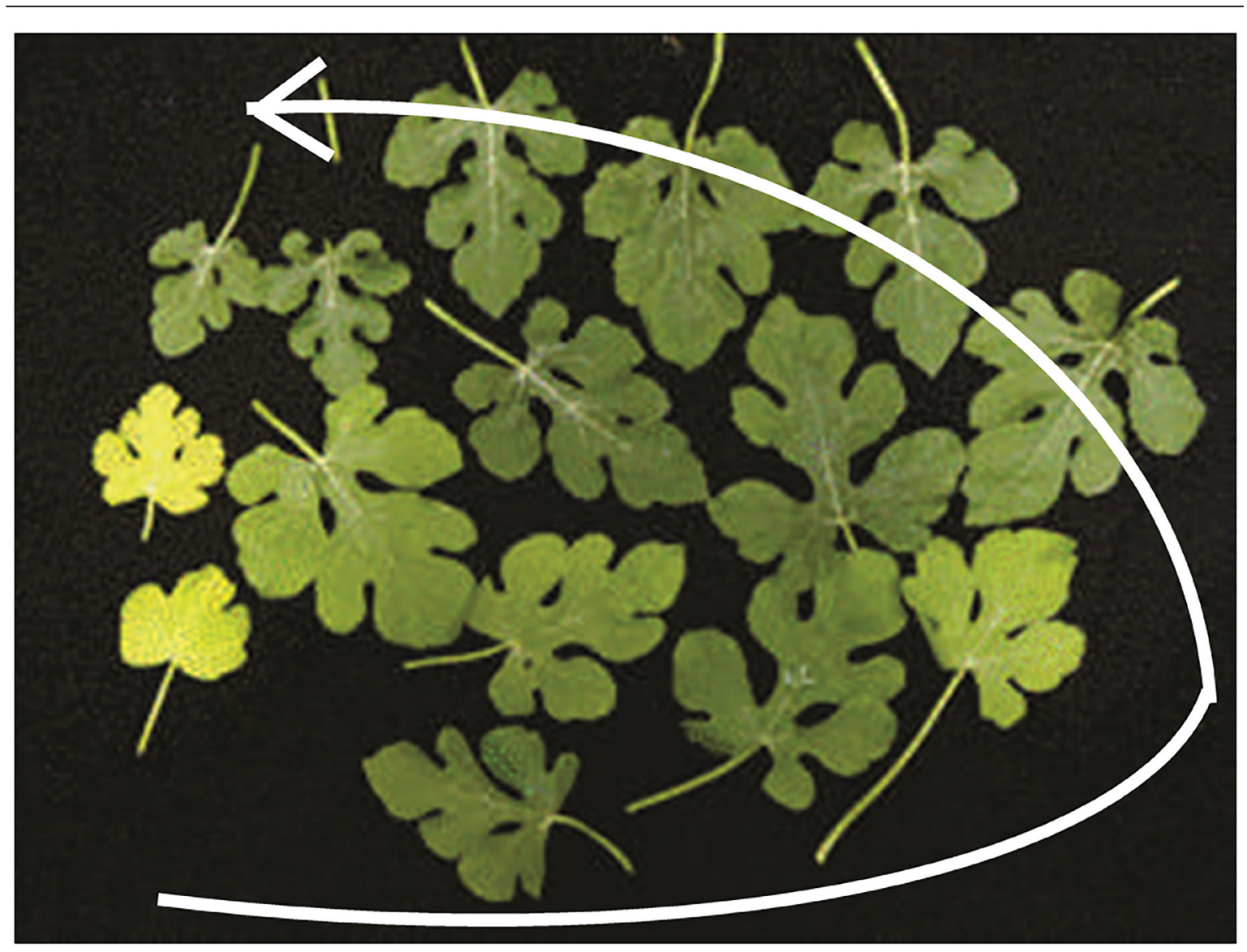

Figura 1. Folhas sem e com clorose (diferentes intensidades) de planta de melancieira após omissão de nitrogênio na solução nutritiva. Seguindo-se a seta, têm-se folhas velhas (muito deficientes em nitrogênio), intermediárias e novas (pouco ou não deficientes).

No início da visualização da clorose nas folhas velhas, os teores de $\mathrm{N}$ nas folhas velhas, intermediárias e novas foram de 9,7; 31 e $37,5 \mathrm{~g} \mathrm{~kg}^{-1}$, respectivamente, caracterizando redistribuição de $\mathrm{N}$ para partes jovens da planta. Este fenômeno ocorre devido à alta mobilidade do nutriente na planta e da necessidade deste em atender órgãos em franco crescimento (Hawkesford et al., 2012). Por outro lado, na mesma época e em folhas da mesma posição de plantas de solução nutritiva completa, os teores de $\mathrm{N}$ foram 44,5; 55,6 e $59,5 \mathrm{~g} \mathrm{~kg}^{-1}$, respectivamente. $\mathrm{O}$ teor de $\mathrm{N}$ da folha diagnóstica no tratamento com solução nutritiva completa foi de $49,5 \mathrm{~g} \mathrm{~kg}^{-1}$, que se encontra na faixa de 25 a $50 \mathrm{~g} \mathrm{~kg}^{-1}$, considerada adequada por Trani \& Raij (1997) para a cultura da melancieira.

Transcorridos 15 dias da omissão de $\mathrm{N}$ a clorose foi observada em folhas mais velhas, localizadas até o sexto nó foliar da haste principal, da base para o ápice da planta. Nas hastes laterais (hastes de segunda ordem), foi observado amarelecimento das folhas velhas situadas até quarto nó foliar. Com a permanência da deficiência de N, a clorose avançou para as folhas localizadas no ápice das hastes.

Após 18 dias da omissão de $\mathrm{N}$, houve interrupção na emissão de brotações na haste principal após o nono nó foliar, enquanto nas hastes secundárias e terciárias não houve formação de hastes laterais. A clorose expandiuse atingindo folhas até o décimo nó da haste principal. Folhas novas das hastes principal e laterais apresentaram tamanho menor do que as respectivas folhas de plantas cultivadas em solução nutritiva completa. Jong et al. (2014) verificaram que Arabidopsis thaliana, quando supridas com baixa dose de N, reduziu a emissão de hastes laterais em razão do direcionamento da auxina para o crescimento da haste principal. Aos 23DAO de N, foi observado que todas as folhas da planta estavam completamente amarelecidas. Neste momento também foi observado internódios curtos na haste principal, entre a primeira e a sexta folha partindo do ápice 
para a base. Nas hastes laterais, internódios curtos foram observados a partir da quarta folha. Com a permanência da omissão de $\mathrm{N}$, houve senescência foliar, possivelmente pela carência de N na planta reduzir a síntese de aminoácidos e ácidos nucleicos muito demandados no metabolismo da planta (Afrousheh et al., 2010), além de redução na quantidade e na atividade da Rubisco (Bondada \& Syvertsen, 2003). e paralisação do crescimento (Figura 2 A e B), a haste principal de plantas deficientes em $\mathrm{N}$ apresentou comprimento médio de 2,24 $\mathrm{m}$, enquanto plantas cultivadas com solução nutritiva completa foi de 3,97 m.

A matéria seca de hastes e folhas (hastes + folhas) foi de 21,5 $\mathrm{g} \mathrm{planta}^{-1}$ para planta deficiente em $\mathrm{N}$ e de 107, $1 \mathrm{~g} \mathrm{planta}^{-1}$ para plantas cultivadas com solução nutritiva completa.

Com a clorose em toda a parte aérea

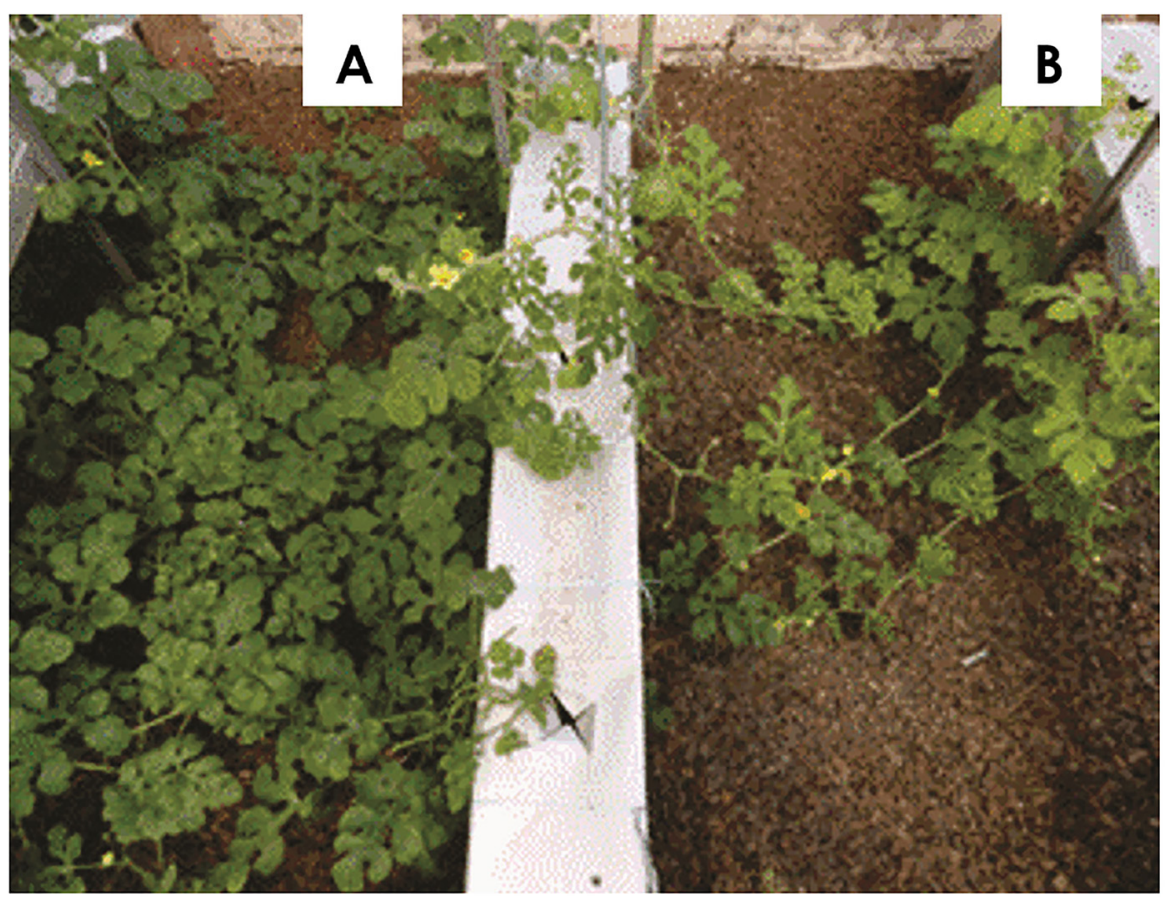

Figura 2. Plantas de melancieira cultivadas com solução nutritiva completa (A) e com omissão de nitrogênio (B).

Fósforo (P)

O sintoma inicial da deficiência de $P$ na melancieira surgiu 15 dias após a omissão do nutriente, quando as plantas estavam com 53 dias de ciclo. De acordo com Grangeiro \& Cecílio Filho (2005), nesta época, a melancieira apresenta alta demanda de $\mathrm{P}$ pois acumulou $46 \%$ do total de $\mathrm{P}$ absorvido entre 45 e 60 dias após o transplante.

A deficiência de $\mathrm{P}$ foi caracterizada por clorose uniforme nas folhas mais velhas, situadas até o quarto nó, da base para o ápice das três principais hastes da planta (Figura 3). Sintomas semelhantes de deficiência de $P$ foram observados por Silva (2013), na cultura do pimentão.

No início da visualização do sintoma de deficiência de $P$, os teores deste nutriente nas folhas velhas, intermediárias e novas eram de 1,4; 2,0 e 3,2 $\mathrm{g} \mathrm{kg}^{-1}$, respectivamente, enquanto nas respectivas folhas de plantas cultivadas com solução nutritiva completa eram 6,9; 6,7 e 5,7 g $\mathrm{kg}^{-1}$, respectivamente. Comparando os teores das folhas de plantas deficientes e suficientes em $P$, percebeu-se que houve redistribuição de $P$ das folhas velhas para as folhas mais novas. Isto ocorreu devido à alta mobilidade do P no floema, levando à planta submetida à deficiência deste nutriente redistribuí-lo para atender a demanda de tecidos novos e em crescimento (Hawkesford et al., 2012).

Somente o teor de $\mathrm{P}$ na folha nova da planta cultivada em solução nutritiva com omissão de $P$ situou-se na faixa de teores adequados (3 a $7 \mathrm{~g} \mathrm{~kg}^{-1}$ ). Embora as folhas intermediárias tivessem o teor aquém da faixa, 
não apresentaram sintomas de deficiência. Em decorrência da visualização dos sintomas serem a última etapa dentre uma sequência de distúrbios metabólicos ocorridos em plantas sob deficiência nutricional, certamente ocorreram eventos a nível celular. Conforme Lim et al. (2007) inicialmente ocorrem alterações nos cloroplastos, mas o núcleo e as mitocôndrias celulares permanecem intactos, sem ser notada a deficiência, e somente após a ocorrência da desintegração das membranas plasmática e do vacúolo, os sintomas tornam-se visíveis.

$\mathrm{Na}$ folha diagnóstica das plantas cultivadas com solução nutritiva completa, o teor de $\mathrm{P}$ foi de $6,7 \mathrm{~g} \mathrm{~kg}^{-1}$, considerado dentro da faixa de teores adequados para a cultura da melancieira por Trani \& Raij (1997).

Aos 27 DAO de $P$, foi visualizada clorose em todas as folhas entre o primeiro e nono nó foliar, da base para ápice da haste principal, com amarelecimento mais intenso até a quinta folha basal. Nas folhas intermediárias da haste principal, entre o décimo e décimo sétimo nó foliar, foram observadas manchas cloróticas distribuídas no limbo foliar, porém mais concentradas nas margens, com algumas pontuações necróticas. Esses sintomas se intensificaram das margens para o centro das folhas. Nas hastes secundária e terciária foi observado leve perda da cor verde nas folhas mais velhas (até a sexta folha) e as folhas intermediárias entre o décimo primeiro e décimo quinto nó foliar, do ápice para a base, apresentaram clorose iniciando-se na margem para o centro foliar. Nas hastes laterais as folhas entre o primeiro e o quarto nó foliar, da base para o ápice, foi visualizado algumas manchas cloróticas, sendo mais concentrada nas margens das folhas.

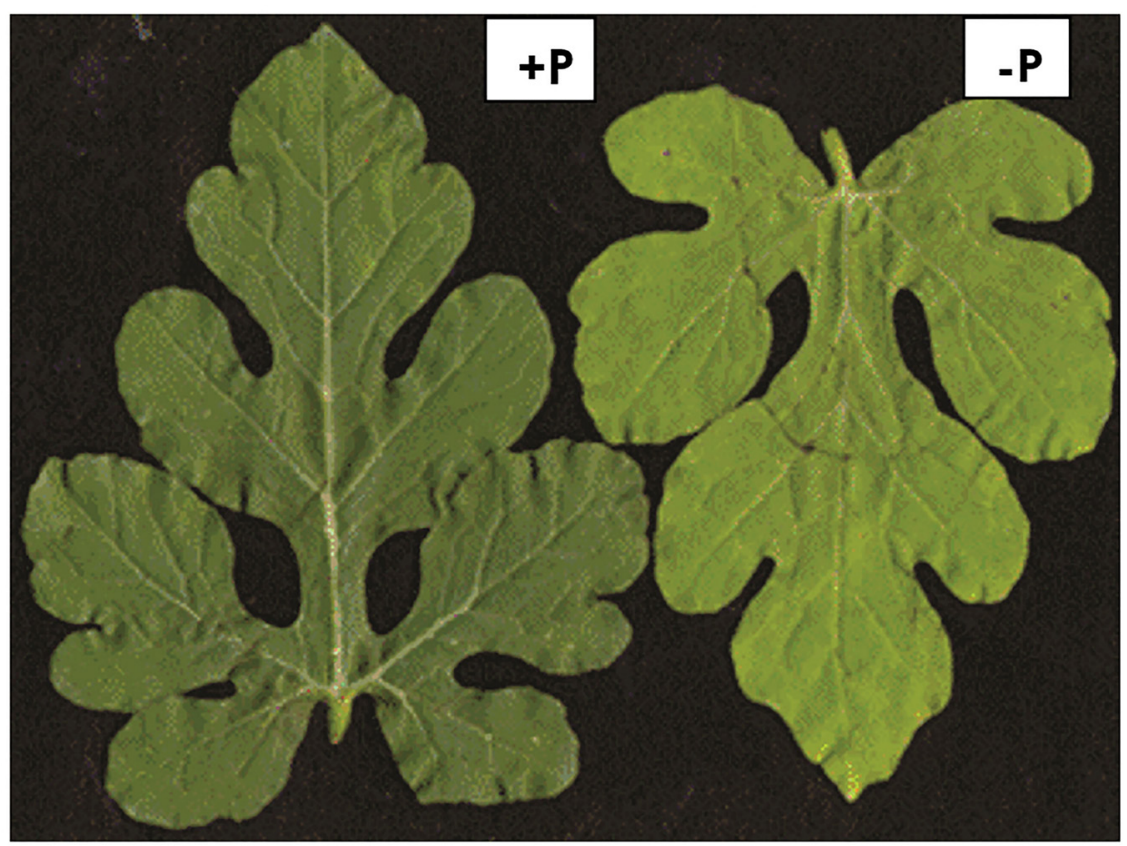

Figura 3. Folhas velhas de mesma posição em plantas de melancieira cultivadas com solução nutritiva completa (+P) e com omissão de fósforo (clorose) (-P).

O amarelecimento das folhas deficientes em $\mathrm{P}$ pode ser explicado em função da decomposição de clorofilas, que ocorrem devido à diminuição da eficiência do sistema fotossintético, causado pela redução na síntese de ATP e da regeneração da Rubisco (Lin et al., 2009), da capacidade de captura de fótons e sua utilização no fotossistema II (Xu et al., 2007), situação essa que causa alterações estruturais nas membranas dos cloroplastos (Fan et al.,
2014).

Não houve paralisação do crescimento da melancieira com a deficiência de P. As plantas deficientes em $\mathrm{P}$ apresentaram haste principal com 3,52 m, enquanto plantas em solução nutritiva completa tinham $3,97 \mathrm{~m}$. Quanto ao acúmulo de matéria seca em hastes e folhas (hastes + folhas), a diferença entre as duas situações foi de cerca de $25 \mathrm{~cm}$, sendo constatadas 82,82 e 107,08 $\mathrm{g}_{\text {planta }^{-1}}$ para as 
plantas com omissão de $\mathrm{P}$ e de solução nutritiva completa, respectivamente. Possivelmente, a pequena diferença no comprimento da planta e acúmulo de matéria seca de hastes mais folhas esteja relacionado ao fato das plantas terem baixa demanda por este nutriente quando comparado com $\mathrm{N}$ e K por exemplo, e ter, durante a evolução da espécie, desenvolvido mecanismos eficientes de armazenamento, de utilização e de reciclagem de fósforo inorgânico interno, reduzindo o consumo de $P$ e redistribuindo o $\mathrm{P}$ dos tecidos velhos para os tecidos jovens. Silva Júnior et al. (1995) também não constataram paralisação do crescimento do pepino, após a omissão de $\mathrm{P}$ da solução nutritiva.

\section{Potássio (K)}

O sintoma visual de deficiência de $K$ foi observado quando foram decorridos 17 DAO do nutriente e 55 dias de ciclo, quando a melancieira apresenta alta demanda por este nutriente que, de acordo com Grangeiro \& Cecílio Filho (2005), ocorre entre 45 a 60 dias após o transplante.

Inicialmente, o sintoma de deficiência de $K$ caracterizou-se por leve clorose nas margens das folhas mais velhas (Figura 4A) situadas até $\mathrm{O}$ sexto nó foliar, da base para o ápice das três hastes principais da planta. Sintomas semelhantes de deficiência de $K$ também foram descritos por Wiwart et al. (2009), em feijão-fava, tremoço amarelo e ervilha.

Possivelmente, a clorose nas folhas velhas da melancieira ocorreu devido à drástica redução da clorofila nestes tecidos (Reddy \& Zhao, 2005), pois a deficiência de $K$ afeta negativamente a translocação de fotoassimilados de fontes para drenos, resultando no acúmulo de carboidratos nas folhas (Zhao et al., 2001). Para Jin et al. (201 1), a maior influência da deficiência de K sobre a fotossíntese pode ser atribuída à redução da condutância do mesófilo e menor capacidade de fixação de $\mathrm{CO}_{2}$.

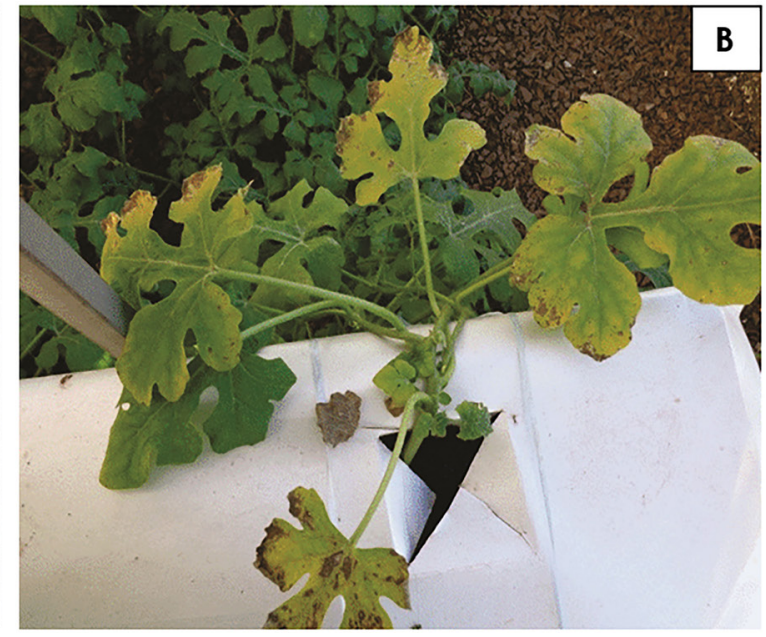

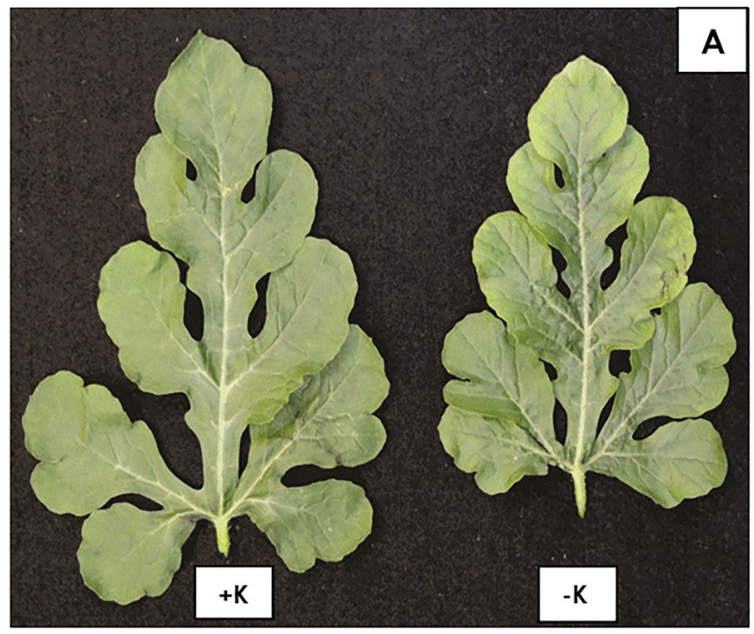

Figura 4. Folhas velhas de planta de melancieira com clorose na margem (-K) em comparação à folha de mesma posição, sem sintoma, de plantas nutridas em potássio (+K) (A), e evolução de clorose para necrose marginal (B).

Aos 17 DAO de K, quando visualizada a deficiência, os teores de $K$ nas folhas velhas, intermediárias e novas foram de 7,1; 9,4 e 13,4 $\mathrm{g} \mathrm{kg}^{-1}$, respectivamente, enquanto nas folhas de mesma posição de plantas cultivadas com solução nutritiva completa os teores foram maiores sendo 22,4; 25,2 e 23,5 g kg-1, respectivamente. Na folha diagnóstica, o teor de $\mathrm{K}$ foi de 19,3 $\mathrm{g} \mathrm{kg}^{-1}$ que, de acordo com Trani \& Raij (1997), encontra-se abaixo da faixa de $K$ considerada adequada para melancieira, que é de 25 a $40 \mathrm{~g} \mathrm{~kg}^{-1}$. Porém, nestas plantas não foi visualizado sintoma de deficiência nutricional. Transcorridos 22 DAO de K, foi observado que os sintomas de deficiência visualizados inicialmente ficaram mais acentuados, principalmente nas folhas compreendidas entre o primeiro e sexto nó foliar, da base para o ápice, evoluindo de clorose leve marginal para clorose mais severa espalhada por toda a folha (Figura 4B). Na haste principal, foi visualizada clorose marginal leve nas folhas compreendidas entre 
o sexto e o vigésimo terceiro nó foliar, do ápice para base da planta. Nas hastes laterais, iniciouse a clorose marginal nas folhas situadas até o quarto nó da base da haste. Nas demais folhas, nenhum sintoma foi observado.

Com a permanência da omissão de $K$ na solução nutritiva, os sintomas de deficiência foram se espalhando e se intensificando da base para o ápice da planta. Deste modo, muitos processos metabólicos foram prejudicados, pois, de acordo com Hawkesford et al. (2012), o K na planta desempenha funções imprescindíveis para ativação enzimática, síntese de carboidratos, ácidos nucleicos e proteínas, osmoregulação das células e fotossíntese.

Aos 25 DAO de K, foi observado que as folhas mais próximas da base da haste principal, situadas até o quarto nó foliar, apresentaram pequenas áreas de tecidos necrosados, sendo mais intensa nas margens das folhas. Houve coalescência de pequenas necroses que formaram manchas necróticas maiores. Ainda nas folhas da haste principal, compreendidas entre o quinto e o vigésimo terceiro nó foliar, da base para o ápice, foi observada clorose distribuída por toda folha e necrose nos tecidos localizados na margem foliar (Figura 4B). Apenas os tecidos próximos à nervura central, apresentaram cor verde. Folhas compreendidas entre o vigésimo quarto e trigésimo nó foliar, da base para o ápice caulinar, apresentaram clorose marginal, enquanto folhas de ordem superior não tinham sintoma de deficiência nutricional. Nessa época, todas as folhas de hastes laterais apresentavam clorose marginal, caracterizando a escassez de K para atender a demanda de folhas jovens. As folhas mais velhas destas hastes laterais, entre o primeiro e quarto nó foliar, apresentaram pequenas áreas de tecidos necrosados.

Os tecidos necrosados são decorrentes do acúmulo de putrescina, poliamina que em altas concentrações causa desequilíbrios celulares e necrose de tecidos vegetais (Pathak et al., 2014), que é resultante da baixa disponibilidade de $\mathrm{K}$ e síntese de proteínas (Hawkesford et al., 2012). Outra hipótese para explicação da necrose de tecidos corresponde à baixa atividade fotossintética da planta. De acordo com Jin et al. (2011), em plantas sob deficiência de $\mathrm{K}$, a baixa concentração de $\mathrm{CO}_{2}$ nos cloroplastos pode levar a desativação da enzima rubisco (Weng et al., 2007), possivelmente pela inibição do ciclo de redução fotossintética do carbono (Ciclo de Calvin) afetando o aparato fotossintético. Com a limitação da fixação de $\mathrm{CO}_{2}$, o fluxo de elétrons para $\mathrm{O}_{2}$ é intensificado promovendo o acúmulo de espécies reativas de oxigênio (ERO) nos cloroplastos, que são altamente danosas às membranas, causando a degradação da clorofila e desencadeando o processo de clorose e necrose nas folhas (Cakmak, 2005).

O K, assim como o P, não foi um nutriente que paralisou o crescimento da planta. Contudo, foi constatado diminuição do tamanho da haste e no acúmulo de matéria seca. Plantas com deficiência de K apresentaram 3,02 m de haste principal, enquanto hastes de plantas em solução nutritiva completa mediam 3,97 m. Quanto ao acúmulo de matéria seca de hastes e folhas (hastes + folhas), verificou-se maior diferença entre plantas deficientes (67,4 $\left.\mathrm{g} \mathrm{planta}^{-1}\right)$ e com suficiência de $K\left(107,08 \mathrm{~g}\right.$ planta $\left.^{-1}\right)$. Esse fato pode ser explicado pela necrose das margens foliares, impedindo o crescimento e acúmulo de matéria seca neste órgão da planta.

Cálcio (Ca)

O sintoma visual de deficiência de Ca foi observado 12 DAO do nutriente quando haviam sido transcorridos 50 dias do ciclo que, de acordo com Grangeiro \& Cecílio Filho (2005), é quando a melancieira apresenta a maior demanda, entre 45 e 60 após o transplante. Inicialmente os sintomas foram caracterizados pela deformação e clorose das margens nas folhas novas, localizadas até a quarta folha a partir do ápice das hastes principais e laterais (Figura 5A e B). Sintoma semelhante foi observado por Alarcón et al. (1999), na cultura do melão.

O teor do nutriente presente nas folhas novas com sintoma de deficiência de Ca foi 1,8 $\mathrm{g} \mathrm{kg}^{-1}$, enquanto nas mesmas folhas de plantas com solução nutritiva completa foi $11,2 \mathrm{~g} \mathrm{~kg}$ 1. Hawkesford et al. (2012) relataram que o Ca é nutriente de pouca mobilidade na planta e limitada redistribuição via floema. Por isso, 

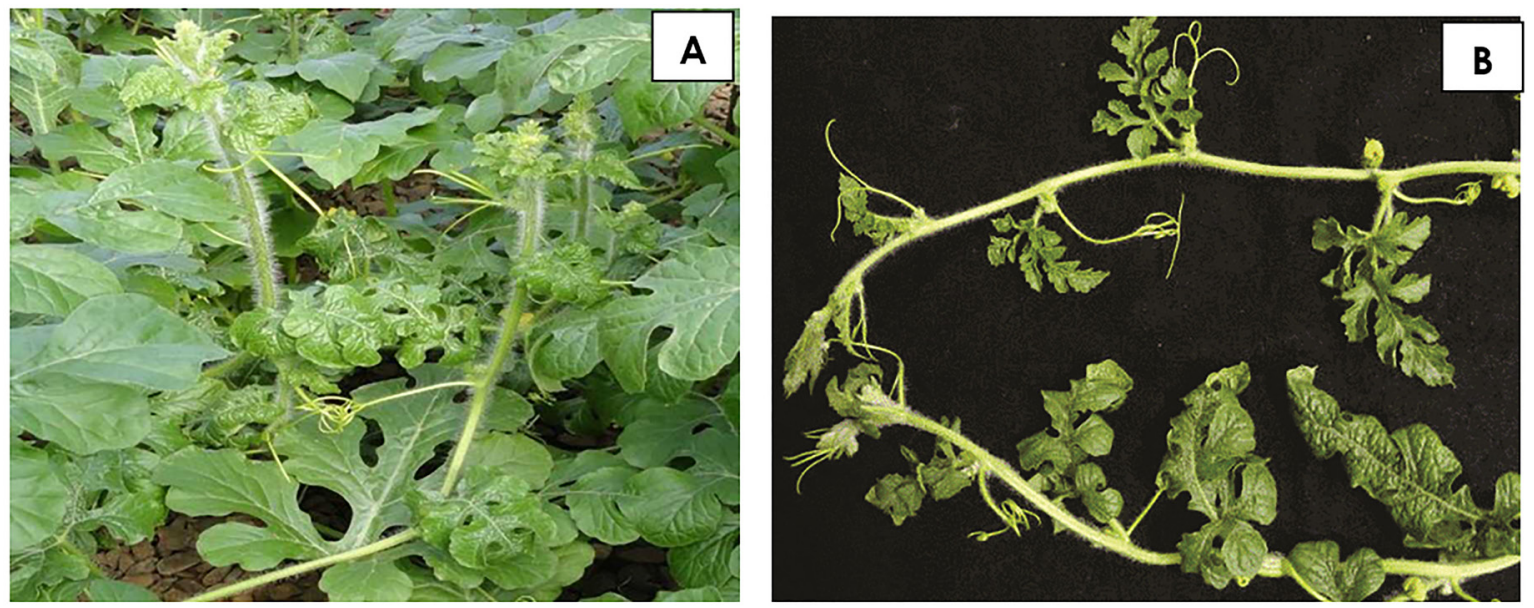

Figura 5. Folhas novas de planta de melancieira deformadas e com clorose causadas por deficiência de cálcio (A), parte apical da haste de planta cultivada com solução nutritiva completa (superior) e com omissão de cálcio (inferior) (B).

planta cultivada em meio com escassez de $\mathrm{Ca}$ tem o aparecimento do sintoma de deficiência nas partes mais jovens da planta, pois o $\mathrm{Ca}$ presente nos tecidos de órgãos velhos da planta não consegue ser redistribuído para atender a demanda de tecidos novos.

O teor de Ca na folha diagnóstica da melancieira cultivadas em solução nutritiva completa foi $8,5 \mathrm{~g} \mathrm{~kg}^{-1}$, abaixo da faixa de $\mathrm{Ca}$ foliar considerada adequada por Trani \& Raij (1997), que é de 25 a $50 \mathrm{~g} \mathrm{~kg}^{-1}$. Porém, nestas plantas não foi visualizado sintoma de deficiência nutricional.

Aos 17 DAO de Ca, foi observada necrose do meristema da haste principal, quatro dias depois, as folhas mais novas das hastes principais, até a décima segunda folha a partir da ponta da haste, apresentaram-se encarquilhadas e com as margens encurvadas para baixo (Figura 6).

O limbo foliar mostrou-se áspero, ondulado e com intensificação da necrose dos tecidos. A necrose dos tecidos de órgãos novos pode ser explicada pela maior ação da poligalacturonase em plantas deficientes em Ca (Serrano et al., 2002), que degrada pectatos de cálcio responsáveis pela estabilidade de membranas e paredes celulares (Hawkesford et al., 2012). Os sintomas de folhas novas encarquilhadas nas margens, onduladas, lesões necróticas e necroses dos meristemas na deficiência de Ca também foi observado em Serrano et al. (2002), em meloeiro.

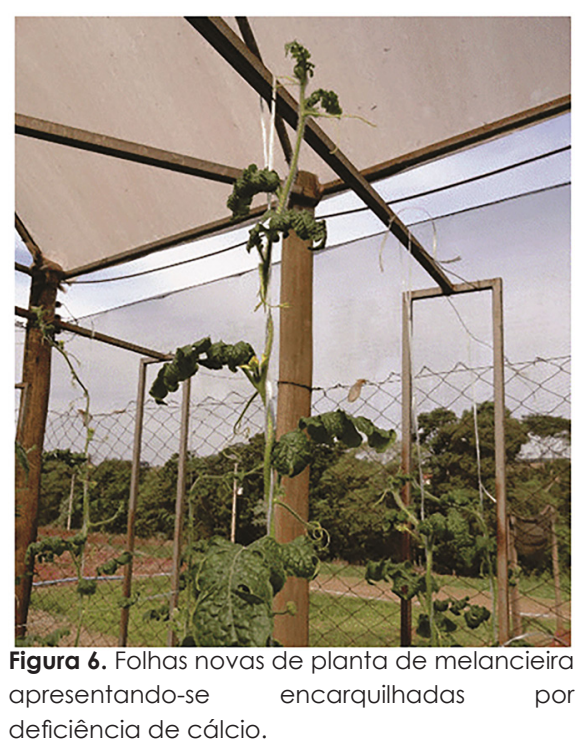

Nas folhas velhas e intermediárias das hastes principais não foi observado sintoma de deficiência. Aos 23 DAO de Ca, foi observado que os quatro internódios próximos ao ápice caulinar apresentavam-se curtos em relação aos de plantas em solução nutritiva completa. Neste momento, a haste principal de plantas deficientes media $3,03 \mathrm{~m}$, enquanto de plantas nutridas em Ca media $3,97 \mathrm{~m}$. A quantidade de matéria seca de hastes e folhas (hastes + folhas), 11 dias após a visualização do sintoma de deficiência, foi de 91,51 e 107,08 $\mathrm{g} \mathrm{planta}^{-1}$ para plantas deficientes e suficientes em Ca.

Em plantas deficientes em Ca não houve formação de frutos, possivelmente devido à má formação do grão de pólen ou desenvolvimento inadequado do tubo polínico (Zhou et al., 2013). 
Magnésio (Mg)

O sintoma visual de deficiência de $\mathrm{Mg}$ na cultura da melancieira foi observado aos 16 DAO do nutriente, quando haviam transcorridos 54 dias do ciclo da planta. De acordo com Grangeiro \& Cecílio Filho (2005), a melancieira apresenta a maior demanda de $\mathrm{Mg}$ entre $45 \mathrm{e}$ 60 dias após o transplante, similar ao P, $\mathrm{K}$ e Ca.

Incialmente, o sintoma inicial da deficiência de Mg foi caracterizada por clorose internerval, nas folhas velhas da haste (Figura 7A), localizadas até o quinto nó foliar, da base para o ápice caulinar.

Sintomas similares foram observados por Silva (2013) na cultura do pimentão. Com
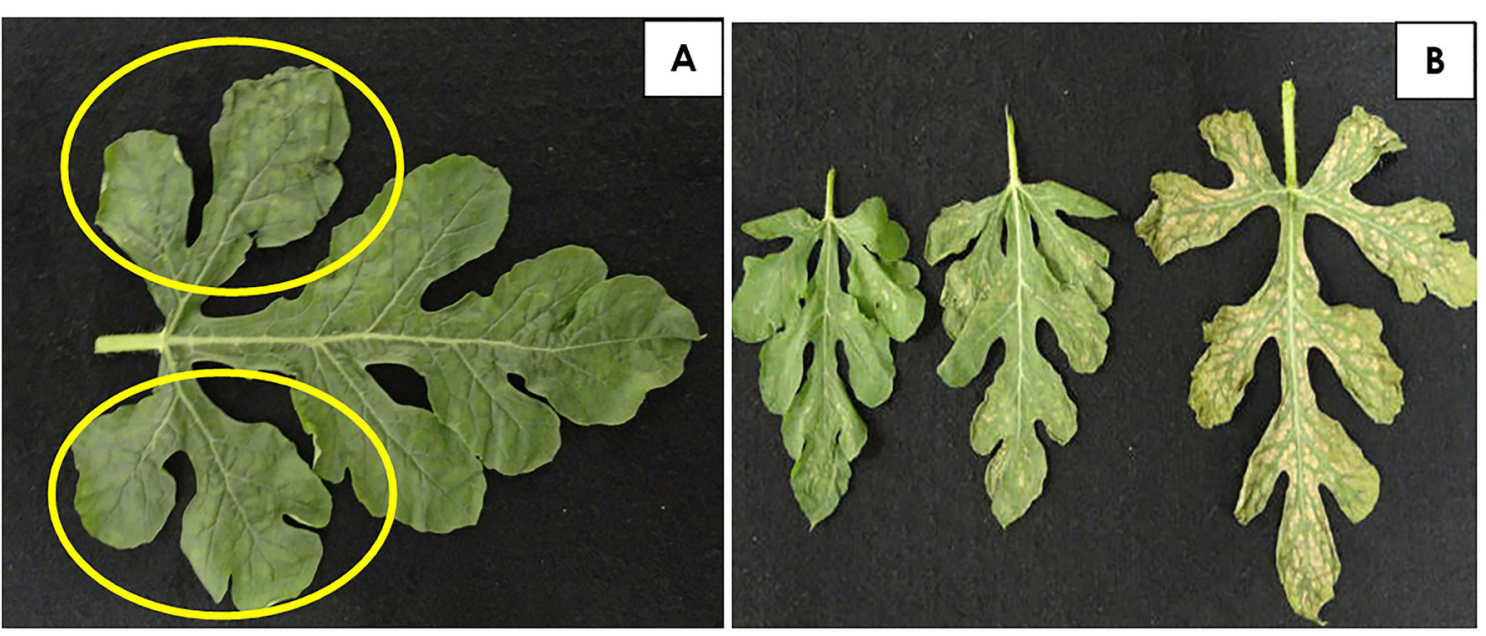

Figura 7. Folha velha de planta de melancieira com início de clorose internerval causada por deficiência de magnésio (A) e evolução para necrose dos tecidos (B).
Os sintomas de deficiência de $\mathrm{Mg}$ ocorreram incialmente nas folhas mais velhas devido à sua alta mobilidade no floema (Hawkesford et al., 2012) e a clorose foliar está relacionada com a decomposição da clorofila. Hermans \& Verbruggen (2005) verificaram que a deficiência de $\mathrm{Mg}$ causou forte redução na concentração de clorofila em Arabidopsis thaliana, devido ao fato do $\mathrm{Mg}$ ser o átomo central da molécula da clorofila e participar das estruturas da membrana do tilacóide e no empilhamento da grana (Hawkesford et al., 2012).

Hermans et al. (2005) verificaram que, na deficiência de $\mathrm{Mg}$ em beterraba, amido foi acumulado nas folhas devido à contínua produção de sacarose e o transporte inadequado via floema para os órgãos drenos. O acúmulo de amido foi maior entre as nervuras a evolução dos sintomas foi observada clorose entre as nervuras do limbo foliar, pontuações esbranquiçadas com contorno irregular, pontuações necróticas com aspecto de "ferrugem", sendo mais intenso nas margens foliares. A partir da coalescência e morte dos tecidos as margens das folhas ficaram encurvadas para cima. Na haste principal, as folhas entre o sétimo e o décimo segundo nó, do ápice para base apresentaram manchas cloróticas distribuídas por todo limbo foliar. As folhas novas dos meristemas nas três hastes principais e laterais não apresentaram nenhum sintoma de deficiência nutricional. das folhas, onde posteriormente surgiram as cloroses internervais (Hermans \& Verbruggen, 2005). Isto pode explicar o aparecimento de clorose internerval nas folhas com deficiência de Mg aos 16 dias após a aplicação do tratamento com omissão deste nutriente.

Quando havia decorrido 16 DAO de Mg, os teores de Mg nas folhas velhas, intermediárias e novas foram 1,8; 0,9 e 1,3 $\mathrm{g} \mathrm{kg}^{-1}$, respectivamente, enquanto nas mesmas folhas, porém de plantas cultivadas com solução nutritiva completa, foram 6,6; 6,2 e 3,1 $\mathrm{g} \mathrm{kg}^{-1}$, respectivamente. 0 teor de Mg na folha diagnóstica da melancieira com tratamento de solução nutritiva completa foi 3,5 $\mathrm{g} \mathrm{kg}^{-1}$, que é inferior à faixa de 5 a $12 \mathrm{~g} \mathrm{~kg}^{-1}$, relatada por Trani \& Raij (1997), como adequada à cultura da melancieira. Porém, nestas plantas não foi visualizado sintoma de deficiência nutricional. 
Aos 18 DAO de Mg, nas folhas entre o primeiro e décimo sexto nó foliar, das hastes principais, foi observada clorose internerval com evolução para tecidos esbranquiçados e tecidos necrosados. As pontuações esbranquiçadas e necróticas apresentaram contorno irregular, sendo a necrose mais intensa nas margens das folhas. Com a evolução da deficiência houve coalescência de pequenas necroses, eformaram manchas necróticas maiores, seguido da morte dos tecidos das margens das folhas, que ficaram curvados para cima (Figura 7B). As folhas velhas da haste secundária e terciária situadas entre o primeiro e o sexto nó foliar apresentaram manchas necróticas, sendo mais intensas na margem das folhas, manchas cloróticas e acinzentadas nas folhas situadas entre o sétimo e décimo primeiro nó foliar. As folhas novas das hastes das três hastes principais e laterais não apresentaram sintomas de desordem nutricional.

Com a permanência da omissão de $\mathrm{Mg}$, os sintomas deficiência nas folhas foram se intensificando e gradativamente avançado da base em direção ao ápice das plantas afetando o seu desenvolvimento. A deficiência de Mg limita o fluxo de energia luminosa e fixação do carbono, que aumenta a formação de espécies reativas de oxigênio (ERO), as quais em altas concentrações causam lesões nos cloroplastos (Cakmak \& Kirkby, 2008). Assim, de acordo com Hawkesford et al. (2012), plantas deficientes em Mg têm diminuição na capacidade fotossintética e a produção de ERO excede a capacidade de desintoxicação das enzimas levando à clorose e posterior necrose das folhas devido à fotoxidação dos pigmentos dos cloroplastos. Com 25 DAO de $\mathrm{Mg}$, foi observado que nas folhas, situadas entre o primeiro e o vigésimo terceiro nó foliar na haste principal, entre o primeiro e o décimo nó foliar na haste secundária e terciária, do primeiro ao quarto nó foliar na haste lateral, partindo da base para o ápice, necroses por todo o limbo foliar, exceto nas nervuras que permaneceram com a coloração verde (reticulado grosso).

A deficiência de $\mathrm{Mg}$, assim como observado para P e K, não causou paralisação do crescimento da melancieira, mas o afetou negativamente. Aos 25 DAO de Mg, o comprimento da haste principal da melancieira foi de 3,42 m, enquanto da planta em solução completa foi de $3,97 \mathrm{~m}$. Por outro lado, ao contrário do $\mathrm{P}$ e semelhante ao $\mathrm{K}$ devido causar acentuada necrose de tecidos foliares internervais e marginais, o acúmulo de matéria seca de hastes e folhas (hastes + folhas) de plantas deficientes em Mg foi reduzido em $42 \%$ em relação à matéria seca de hastes e folhas (hastes + folhas) de plantas cultivadas em solução nutritiva completa, 107,08 $\mathrm{g} \mathrm{planta}^{-1}$.

\section{Conclusões}

A omissão de nutrientes em plantas em início da frutificação, os sintomas de deficiências $\mathrm{N}$ e Ca foram os primeiros a serem observados.

A deficiência de $N$ causa cessação do crescimento, inibição de hastes laterais, clorose generalizada e necrose em folhas velhas.

A omissão de $P$, os sintomas de deficiência ocorrem inicialmente em folhas velhas, com áreas cloróticas e enrugadas, que posteriormente progridem para necrose.

A deficiência de $K$ causa sintomas de deficiência em folhas velhas, que começa com clorose marginal, progredindo para todo o limbo e posteriormente evoluindo para necrose.

A deficiência de $\mathrm{Ca}$, as folhas novas ficam deformadas, com clorose, necrose marginal, margens encurvadas para baixo, limbo foliar grosso, enrugado e com necrose nos meristemas.

A omissão de $\mathrm{Mg}$ inicialmente provoca sintomas de deficiência em folhas velhas, com clorose internerval, pontuações esbranquiçadas e necróticas com contorno irregulares, morte de tecidos, reticulado grosso e margens das folhas encurvada para cima.

Os teores de N, P, K, Ca e Mg na folha e por ocasião de deficiência são 9,$7 ; 1,4 ; 7,1 ; 1,8$ e $1,8 \mathrm{~g} \mathrm{~kg}^{-1}$, respectivamente.

\section{Referências}

Afrousheh, M., Ardalan, M., Hokmabadi, H., Afrousheh, M. 2010. Nutrient deficiency disorders in Pistacia vera seedling rootstock in relation to eco-physiological, biochemical characteristics and uptake pattern of nutrientes. Scientia Horticulturae 124:141-148.

Alarcón, A.L., Madrid, R., Egea, C., Guillén, I. 1999. Calcium deficiency provoked by the application of different forms and concentrations of $\mathrm{Ca}^{2+}$ 
to soil-less cultivated muskmelons. Scientia Horticulturae 81:89-102.

Ayala-Silva, T., Beyl, C.A. 2005. Changes in spectral reflectance of wheat leaves in response to specific macronutrient deficiency. Advances in Space Research 35: 305-317.

Bataglia, O.C., Furlani, A.M.C., Teixeira, J.P.F., Furlani, P.R., Gallo, J.R. 1983. Métodos de análise química de plantas. Instituto Agronômico de Campinas, Campinas, Brasil. 48 p (Boletim Técnico 78).

Bondada, B.R., Syvertsen, J.P. 2003. Leaf chlorophyll, net gas exchange and chloroplast ultrastructure in citrus leaves of different nitrogen status. Tree Physiology 23: 553-559.

Cakmak, I. 2005. The role of potassium in alleviating detrimental effects of abiotic stresses in plants. Journal of Plant Nutrition and Soil Science 168: 521-530.

Cakmak, I., Kirkby, E.A. 2008. Role of magnesium in carbon partitioning and alleviating photooxidative damage. Physiologia Plantarum 133: 692-704.

Fan, J., Cui, Y., Wan, M., Wang, W., Li, Y. 2014. Lipid accumulation and biosynthesis genes response of the oleaginous Chlorella pyrenoidosa under three nutrition stressors. Biotechnology for Biofuels 7:1-14.

Feller, U., Anders, I., Demirevska, K. 2008. Degradation of rubisco and other chloroplast proteins under abiotic stress. General and Applied Plant Physiology 34: 5-18.

Grangeiro, L.C., Cecílio Filho, A.B. 2005. Acúmulo de e exportação de nutrientes pela melancieira sem sementes, híbrido Shadow. Científica 33: 6974.

Hawkesford, M., Horst, W., Klchey T., Lambers, H., Schjoerring, J., Moller, I.S., White, P. 2012. Functions of macronutrients In: Marschner, P. (ed). Mineral Nutrition of Higher Plants. Academic Press, London, p. 135-189.

Hermans, C., Bourgis, F., Faucher, M., Strasser, R.J., Delrot, S., Verbrugger, N. 2005. Magnesium deficiency in sugar beets alters sugar partitioning and phloem loading in young mature leaves. Planta 220: 541-549.

Hermans, C., Verbrugger, N. 2005. Physiological characterization of $\mathrm{Mg}$ deficiency in Arabidopsis thaliana. Journal of Experimental Botany 56: 2153-2161.

Hoagland, D.R., Arnon, D.I. 1950. The water culture method for growing plants without soils. California Agricultural Experimental Station,
Berkeley, USA. 347p.

Ji-Yong, S., Xiao-Bo, Z., Jie-Wen, Z., Kai-Liang, W., Zheng-Wei, C., Xiao-Wei, H., De-Tao, Z., Holmes, M. 2012. Nondestructive diagnostics of nitrogen deficiency by cucumber leaf chlorophyll distribution map based on near infrared hyperspectral imaging. Scientia Horticulturae 138: 190-197.

Jin, S.H., Huang, J.Q., Li, X. Q., Zheng, B.S, Wu, J. S., Wang, Z.J., Liu, G.H., Chen, M. 2011 . Effects of potassium supply on limitations of photosynthesis by mesophyll diffusion conductance in Carya cathayensis. Tree Physiology 31: 1142-1151.

Jong, M., George, G., Ongaro, V., Williamson, L., Willettes, B., Ljung, K., MCCULLOCH, H. LEYSER, O. 2014. Auxin and strigolactone signaling are required for modulation of Arabidopsis shoot branching by nitrogen supply. Plant Physiology 166: 384-395.

Lim, P.O., Kim, H.J., Nam, H.G. 2007. Leaf senescence. Annual Review of Plant Biology 58: $115-136$.

Lin, ZH., Chen, LS., Chen, RB., Zhang, FZ., Jiang, HX., Tang, N. 2009. CO assimilation, ribulose1,5-bisphosphate carboxylase/oxygenase, carbohydrates and photosynthetic electron transport probed by the JIP-test, of tea leaves in response to phosphorus supply. Plant Biology 9: 1-12.

Pathak, M.R., Silva, J.A.T., Wani, S.H. 2014. Polyamines in abiotic stress tolerance through transgenic approaches. GM Crops \& Food: Biotechology in Agriculture and the Food Chain 5: 87-96.

Reddy, K.R., Zhao, D. 2005. Interactive effects of elevated $\mathrm{CO}_{2}$ and potassium deficiency on photosynthesis, growth, and biomass partitioning of cotton. Field Crops Research 94: 201-213.

Serrano, M., Amorós, A. Pretel, M.T., MartínezMadrid, M. C., Madrid, R., Romojaro, F. 2002. Effect of calcium deficiency on melon (Cucumis melo L.) texture and glassiness incidence during ripening. Food Science and Technology International 8: 147-154.

Silva, A.Z. 2013. Sintomas de deficiência de macronutrientes em pimentão. 53 f. (Tese de doutorado) - Universidade Estadual Paulista "Júlio de Mesquita Filho", Jaboticabal, Brasil.

Silva Júnior, A.A., Soprano, E., Vizzotto, V.J., Macedo, S.G. 1995. Caracterização de deficiências nutricionais em pepineiro. EPAGRI, Florianópolis, Brasil, 36p (Boletim Técnico 70).

Trani, P.E., Raij, B.Van. 1997. Hortaliças. In: Recomendações de adubação e calagem para 
- Estado de São Paulo. Raij, B.van., Cantarella, H., Quaggio, J.A., Furlani, A.M.C. (eds). Instituto Agronômico de Campinas \& Fundação IAC, Campinas, Brasil. p. 157-164 (Boletim Técnico 100).

Weng, XY., Zheng, CJ., XU, HX., Sun, JY. 2007. Characteristics of photosynthesis and functions of the water-water cycle in rice (Oryza sativa) leaves in response to potassium deficiency. Physiologia Plantarum 131: 614-621.

Wiwart, M., Fordónski, G., Zur-Golazewska, K., Suchowilska, E. 2009. Early diagnostics of macronutrient deficiencies in three legume species by color image analysis. Computers and Electronics in Agriculture 65: 125-132.

Xu, H.X., Weng, X.Y., Yang, Y. 2007. Effect of phosphorus deficiency on the photosynthetic characteristics of rice plants. Plant Physiology 54: 741-748.

Zhao, D., Oosterhuis, D.M., Bernarz, C.W. 2001. Influence of potassium on photosynthesis, chlorophyll content, and chloroplast ultrastructure of cotton plants. Photosynthetica 39: 103-109.

Zhou, L., Lan, W., Jiang, Y., Fang, W., Luan, S. A. 2013. A Calcium-Dependent protein kinase interacts with and activates a calcium channel to regulate pollen tube growth. Molecular Plant 7: 369-376. 